\title{
Improving the adoption of PBS and ABA using diffusion of innovations theory
}

\begin{tabular}{|r|l|}
\hline Journal: & Tizard Learning Disability Review \\
\hline Manuscript ID & TLDR-02-2018-0005.R1 \\
\hline Manuscript Type: & Research Feature \\
\hline Keywords: & $\begin{array}{l}\text { Positive behaviour support, Diffusion, Applied behaviour analysis, Adoption, } \\
\text { Intellectual disability, Learning disabilities }\end{array}$ \\
\hline \multicolumn{2}{|c}{} \\
\hline
\end{tabular}

SCHOLARONE $^{\text {tw }}$

Manuscripts 


\section{Improving the adoption of PBS and ABA using diffusion of innovations theory}

Since it was first described in 1990, positive behaviour support (PBS) has experienced a dramatic surge in its application in practice, particularly in schools in the US (Kern \& Lane, 2018). Applied behaviour analysis (ABA) as a clinical discipline has also experienced significant growth in recent years (Guercio \& Murray, 2014). The relationship between PBS and ABA has been discussed at length in the literature, especially within the ABA field. Dunlap, Carr, Horner, Zarcone and Schwartz (2008) argue that a misunderstanding of PBS by those working in the ABA field has produced confusion and unnecessary division.

\section{Distinguishing between PBS and ABA}

ABA is established as a strong applied science and its contributions to problems of human behaviour are significant. It uses the general principles of learning and behaviour to study, predict and control behaviour rather than observing behaviour and drawing inferences (Fisher, Groff \& Roane, 2011). PBS on the other hand emphasises "context and the macrovariables that exert pervasive influences on behavior that are relatively difficult to isolate with traditional behavior analytic methodologies" (Dunlap et al., 2008, p. 693). PBS and ABA occupy different roles, with PBS being a supports activity (Grey, Lydon \& Healy, 2016) and ABA an intervention activity (Moore \& Cooper, 2003), but both share a commitment to behavioural science (Dunlap, Sailor, Horner \& Sugai, 2009).

Wacker and Berg (2002) describe a tension between the application of models of PBS and $\mathrm{ABA}$ with regard to service delivery (though this tension is underpinned by debate about the scientific merit of PBS as an applied science). Around the same time, Carr and Sidener (2002) endorsed PBS as a behaviour analytic service-delivery framework, similar to Wacker and Berg (2002). In addition, contemporary definitions of PBS do not shy away from its role in service delivery (see Kincaid et al., 2016). However, PBS goes beyond service delivery per 
se, by aligning the approach to the values underpinning modern disability service delivery (Grey, Lydon \& Healy, 2016).

There is however, some evidence of collaboration between PBS and ABA in service delivery. In 2000, Anderson and Freeman described in detail how PBS is a framework for providing services to people with disability through the teaching of skills using the technology of ABA. This approach was later adapted by Rotholz and Ford (2003) in their description of the state-wide implementation of PBS along with ABA, highlighting the contribution of both to improved service delivery.

\section{Method}

\section{Approach}

Innovations such as $\mathrm{PBS}$ and $\mathrm{ABA}$ are communicated through particular channels (messages about the innovation are sent and received) over time among the members of a social system (individuals, informal groups, organisations, subsystems). This communication process is termed diffusion by Rogers (2003) and he argues that communication is the central mechanism contributing to the exchange of information and new ideas. These elements provide a model which one can apply to the development and application of PBS and ABA over time, to identify the influencing factors on their adoption. Using Rogers' theory of diffusion of innovations, the development of PBS and ABA can be constructed beyond simply justifying their origins, describing the events and developments which occurred. Further, opportunities can be identified for improving their adoption in policy and practice.

This paper examines the elements of diffusion in three sets of articles, published between 2006 and 2017, about ABA and PBS from a US context. Two articles were selected because they were published in behaviour analytic journals and represent a variety of 
perspectives on the relationship between PBS and ABA, and they have published replies.

This is somewhat unique because of ABA's historically negative view of PBS (Dunlap et al., 2008), an issue which will be explored below. The third article was selected because, while it briefly references PBS, its value lies in its consideration of factors for the successful diffusion of ABA, which are also appropriate considerations for PBS. The paper ends with an exploration of the context of PBS and ABA in the UK and makes suggestions for improved, collaborative adoption.

\section{Conceptual Framework}

The claims in each article are examined using Wejnert's (2002) conceptual framework (Table 1). This framework integrates twelve variables of diffusion contained within three components: (1) characteristics of the innovation itself which modulate the process of diffusion, (2) characteristics of those adopting the innovation, and (3) the ecological and cultural context of adopting the innovation. These describe how innovations, in this case PBS and ABA, are diffused, or spread, from a source to an adopter. A narrative approach, influenced by Chatman's (1978) concept of story, is used to apply the components of the framework to the articles. The story concept comprises a summary of events, establishes the time, situation, setting and participants, actions, resolutions, and return to the present. The variables in the conceptual framework can be directly applied to the elements present in each 'story'. This paper does not claim to be a comprehensive narrative analysis. Instead it focuses on two aspects of the narrative analysis as described by Lieblich, TuvalMashiach and Zilber (1998): (1) coherence: how parts of the analysis fit together and how they fit with existing theories and previous research. This is achieved by applying diffusion theory and a conceptual framework. (2) Insightfulness: originality in the presentation of the 
story and in the analysis of it. This paper is the first to discuss and present the relationship between PBS and ABA in this way and to offer suggestions for further, successful diffusion.

\section{Findings}

Article 1

Johnson et al.'s (2006) paper is a lengthy critique of PBS which provided an evaluation of the reasons why PBS has been successful compared with ABA in North America. The authors state that PBS has been successful in garnering the support of federal agencies and marketing the model to disability and educational services (p. 63). This is representative of what Wejnert calls "the social entity of innovators". Here, PBS was adopted by large collective adopters (federal agencies) with public consequences to the adoption (change in disability and school practices). The successful adoption of PBS was due to the influence of federal agencies changing school policy and legislation, and the promotion of PBS by disability advocacy groups (e.g. Horner \& Dunlap, 2012). Johnson et al. also note that Federal and state statutes and regulations include PBS as the approach of choice (p. 63). While this is evidence of "political conditions" in Wejnert's framework, the influence of Wejnert's "societal culture" variable in diffusion is also relevant here. For example, how PBS has positively influenced family engagement with schools (Garbacz et al., 2016), and demonstrated effectiveness of supporting people with disabilities and challenging behaviour in the community rather than institutions (LaVigna \& Willis, 2012), both of which are valued by society. The influence of "global uniformity", another variable in Wejnert's conceptual framework for diffusion, on the adoption of PBS is significant. Reactions to the use of aversive interventions in institutions (see Repp \& Singh, 1990) were important in the development of positive approaches to supporting people with challenging behaviour, 
contributing to the development of the PBS framework. Johnson et al. (pp. 64-66) also highlight:

- PBS leaders developed close relationships with federal agencies, especially the US Department of Education, pursued federal funding which permitted widespread dissemination, and focussed on dissemination through bureaucratic processes. These are further examples of the "political conditions" in the ecological component of Wejnert's framework influencing the adoption of PBS.

- The service model of PBS appeals to potential users through promoting common values. The promotion of common values is evident for both disability services (Gore et al. 2013), and schools (Scott, 2007) and is representative of "societal culture" in the cultural component of Wejnert's framework.

- PBS is an organisational focus on service delivery rather than a research agenda. Wejnert's "private consequences" variable relates to adopting innovations which, in the case of PBS, reform social or organisational structures. Because PBS is a systems approach which is designed to account for the organisational system in which support is provided (Dunlap, Sailor, Horner \& Sugai, 2009), the focus of PBS is on promoting practices that can be done by typical people in typical contexts (Horner \& Sugai, 2018). Conversely, ABA is promoted as an applied scientific technology with an international certification process to protect it from bogus practitioners (Shook \& Johnson, 2011).

Responding to Johnson et al., Filter (2007) argued that a strong relationship between ABA and PBS may accomplish broad dissemination of behavioural technology and access to political communities which ABA has struggled to influence. He further suggests ways of enhancing the relationship between PBS and ABA: 
- Presenting PBS research at ABA conferences,

- Publishing data-based studies of PBS in ABA journals,

- $\quad$ PBS professional organisations adopt policies that increase ties with ABA.

These comments draw attention to the way in which ABA and PBS practitioners constitute separate networks of communication. Homophilous networks constitute persons who are similar in some attribute, and in the case of $\mathrm{ABA}$, such attributes may be standardised training, education, and certification (through the Behavior Analyst Certification Board; www.bacb.com). On the other hand, PBS practitioners are from heterophilous networks reflecting their different attributes such as epistemology and philosophical viewpoints. Rogers (2003) argues that homophilous networks are a barrier to diffusion because new ideas usually enter the network through persons with greater power, status, or expertise. These persons mainly interact with one another and therefore set the standard for what information will flow into the network. This is demonstrated in the initial strict criteria for ABA and the initial criticism of PBS by the ABA community. While communication in homophilous networks is generally more effective because attributes are shared between those communicating, heterophilous communication is advantaged by linking dissimilar individuals in a network which permits new, innovative ideas to be more easily communicated (Rogers, 2003). This is demonstrated through the relative rapid international adoption of PBS amongst seemingly disparate groups of professionals and service sectors. So, if practitioners from one network can effectively communicate in the other, ABA and PBS can more efficiently diffuse. A more harmonious relationship between PBS and ABA is now evident through exploration of similar perceptions of practice (Brown, Michaels, Oliva \& Woolf, 2008), and dual professional memberships and special interest groups (Dunlap, et al., 2008). More recently, Dillenburger et al. (2014) has outlined how ABA can be an 
appropriate conceptual framework for multidisciplinary practice, and the Coalition of Behavioral Science Organizations (2018), which is inclusive of the fields of PBS and ABA, has published joint values and guiding principles.

\section{Article 2}

The second debate is in the May 2015 edition of the journal Behavior Analysis in Practice. It included a special section on positive behaviour interventions and supports (PBIS; also known as PBS) featuring a primary paper by Horner and Sugai (2015) which attracted a number of responses. Kincaid et al. (2016) highlight that, historically, PBS has stressed and prioritised different characteristics of definitions and as such, their published definition of PBS was careful to distinguish PBS from approaches which are not PBS, including ABA. Continuing the commentary, Critchfield (2015) criticises ABA's unwavering commitment to what he terms "baerwolfrisleying": the specified criteria for ABA according to the original definition of ABA. Critchfield questions the assumption that practices that correspond to the original ABA criteria are essentially good, and those which do not are bad. He further challenges the ABA community by stating that the reason for ABA's disregard for PBS is that PBS was engineered for scaling-up while ABA (according to the original criteria) is not. This comment by Critchfield reflects the differences in the "social entity" (see Wejnert, 2002) of PBS and ABA, the former which promotes team and system approaches (see Gore et al., 2013) and ecological validity (Carr et al., 2000), while the latter predominantly focuses on interventions delivered by certified individuals (Normand \& Kohn, 2013).

\section{Article 3}


The third debate was in 2017, when the journal The Behavior Analyst published a paper by Critchfield and Reed which critically examined the fundamental features of ABA. The Critchfield and Reed article contributes a critique of the features which influence the adoption of ABA. The authors make explicit reference to target audiences for research including mainstream researchers, funding agencies, and policy makers, directly referring to those persons or organisations which are not only important to the adoption of ABA, but also integral to the adoption of PBS. But for ABA, it is Wejnert's "familiarity with the innovation" variable which is of relevance here. This element explains that the rate of adoption of ABA - all other factors being equal - increases as its novelty decreases. ABA has an overt scientific basis, and this requires audiences to "consume" ABA, but they can only do so when information is presented to them in ways they can understand. But Noone and Chaplin (2017) argue that ABA is presented in a dispassionate and impersonal way, thereby risking accurate understanding. Familiarity is also acquired by observing the outcomes of innovations for those who have adopted them (Wejnert, 2002). This is one aspect which places PBS at a particular advantage over ABA. PBS's commitment to ecological validity necessitates "ordinary people... in ordinary settings under natural conditions including multiple demands, times of stress and the presence of interfering variables" (Singer, 2000, p. 123). Conversely, ABA continues to experience tension with ecological validity, at least with respect to functional analysis methodology (Lloyd \& Kennedy, 2014). The importance of ecological validity in the "scaling-up" of interventions used in typical contexts has been emphasised by Ledford, Hall, Conder and Lane (2015) and remains an issue for ABA in order for it to maximise its diffusion.

These debates have highlighted seven of Wejnert's conceptual framework variables: political conditions, societal culture, global uniformity, private consequences, familiarity with 
the intervention, benefit vs. cost, and social entity. These represent all three main components of Wejnert's conceptual framework suggesting that the framework was successful in identifying the variables seen as contributing to the diffusion of PBS and ABA in these articles. These debates also evidence a change in the perception of the ABA community towards PBS, with PBS more frequently defended within these ABA publications in later years, but they also demonstrate how PBS has leveraged diffusion more effectively than ABA.

\section{Application to the UK and Australian contexts}

This review has drawn primarily upon a North American perspective because of the predominance of authors from this continent; nevertheless, PBS is gaining increased attention in the UK through its recommendation in several policies and professional guidelines. However, there remains an inherent conflict between ABA and PBS which has evolved outside traditional academic debate. NICE (2017) is artificially separating ABA from PBS despite the two being inextricably related. This is not a new observation; NICE's failure to recognise ABA has been evident since at least 2011 (Dillenburger, McKerr \& Jordan, 2014). Murphy (2017) summarises the development of NICE guidelines and highlights that the guidelines pay particular attention to systematic reviews and randomised controlled trials (RCTs). Murphy reminds us that RCTs are not prevalent in the field of learning (intellectual) disabilities. This point has also been noted by Keenan and Dillenburger (2011) in relation to autism, and by Smith (2013) for behaviour analysts. Sturmey (2014) points out the constraints of systematic reviews and RCTs of the intellectual disability literature, giving examples of methodological limitations. The lack of acknowledging ABA in the guidelines can be interpreted through Wejnert's (2002) variable "benefits vs. costs" (see Table 1). Here, NICE is concerned with the absence of what it perceives to be quality evidence from RCTs 
and systematic reviews (the "benefit"). This absence invokes concern with making recommendations for ABA (the "cost"). This situation has undoubtedly influenced the development of the guidelines because of the limitations of the evidence that can be considered, yet the guidelines borrow heavily from ABA, referencing functional assessment, functional analysis, behaviour support plans, and motivating operations. Conversely, the focus on PBS in the UK following the public broadcast of acts at Winterbourne View is now extensive (Allen \& Baker, 2013). In fact, PBS has been exploited by government in the wake of Winterbourne View with the intention to improve the lives of vulnerable people with intellectual disability without an agreed and defined theory nor competencies for PBS (Allen \& Baker, 2013).

The PBS Academy (pbsacademy.org.uk) has established a PBS competency framework and standards for training and practice. A recent evaluation of the Academy identified a need for improved attention to "supporting an increase in knowledge and practice of PBS and connecting more with other professional organisations and family carers" (Denne, 2017, "Impact of the PBS Academy: Key findings and implications", para. 2). These recommendations can be addressed by designing for diffusion which considers how an innovation is noticed, positively perceived, adopted, adapted and implemented (Dearing \& Cox, 2018).

It is generally recognised that Australia has had few promotors of behaviour analysis (see Jones \& Mazzucchelli, 2018) and up until 2018, there was no approved provider of ABA coursework in Australia for behaviour analysts. Feasibly, this is why Australia still has low numbers of Board Certified Behaviour Analysts (Association for Behaviour Analysis Australia, 2018). Because Australia is relatively geographically isolated and home to few behaviour analysts, communication and personal interactions about ABA are limited. These 
are evidence of the eighth variable in Wejnert's (2002) conceptual framework: "geographical settings". This variable hampers the diffusion of ABA in Australia. Programmes in Australia using ABA are predominantly autism- and childhood-aligned, expensive, and frequently parent directed rather than service directed (Couper, 2004). ABA in Australia has been described as a private market (Valentine, 2010), thereby perhaps protecting it from hype and scepticism often experienced in other jurisdictions because those who choose it inherently believe in its evidence and suitability. ABA is recommended in Australia for children with autism (Prior et al., 2011) but there are no formal recommendations for any other demographic group. Conversely, PBS is well publicised in Australian disability policy, but it is inaccurately represented and is overtly aligned with behaviour support plans and restrictive interventions (Hayward, McKay-Brown \& Poed, in press). The authors argue that PBS in Australian disability services was adopted through coercion and imitation, evidence of “political conditions" in Wejnert's (2002) conceptual framework.

\section{Conclusion}

Wejnert's (2002) conceptual framework for the integration of diffusion variables uses three components to describe how innovations are diffused (spread) from a source to an adopter. The three components are (1) characteristics of the innovation itself which modulate the process of diffusion, (2) characteristics of those adopting the innovation, and (3) the ecological and cultural context of adopting the innovation. These components are evident in the discussion of ABA and PBS in the literature. There are differences in the structure of communication networks, with PBS having a heterophilous network for communication contributing to its improved diffusion while the diffusion of ABA has been hampered by what appears to be a more homophilous network. 
The challenge for PBS appears to be sustaining and scaling its use, while for ABA the challenge appears to be with productive collaboration and funding support. Comparing the adoption of PBS with ABA suggests that continued attention to the following issues may encourage the systemic adoption of both disciplines and meet these challenges:

1. Promotion to large collectives, i.e. political groups, organisations, communities, social movements.

2. Inclusion within laws, regulations, policies and guidelines.

3. Matching with the values of society.

4. Consider the requirements for education and training as potential barriers.

5. Focus on service delivery using team and system approaches.

6. Behavioural science should present evidence to the committees and organisations which are responsible for endorsing practices and interventions to directly influence the inclusion of studies using alternative evidence-based methodologies, for example single-subject experimental designs.

The professional divide between PBS and ABA has dramatically narrowed since Johnson et al.'s paper in 2006. PBS openly acknowledges the influence of ABA on its development and has included behavioural science as a core feature since its inception. More recent publications recognise that ABA's initial disregard for PBS was in error, and it has much to learn from PBS's success in marketing. Both PBS and ABA can now focus on collaboratively improving their adoption, guided by diffusion of innovations theory. The successful adoption of both PBS and ABA has obvious benefits for service users, and Dunlap et al. (2008) summarise this well:

"it is important to emphasize that the distinctions between PBS and ABA do not reflect an adversarial relationship. On the contrary, PBS and ABA occupy 
somewhat different niches, and it is expected that the products of the two approaches will result in mutual benefits" (p. 693).

ABA has guided PBS towards behavioural science; PBS can now guide ABA towards wider adoption.

\section{References}

Allen, D. \& Baker, P. (2013), “Editorial”, International Journal of Positive Behavioural Support, Vol. 3 No. 2 pp. 3-4.

Anderson, C.M. \& Freeman, K.A. (2000), "Positive behaviour support: Expanding the application of applied behaviour analysis", The Behavior Analyst, Vol 2 No. 1, pp. 8594.

Association for Behaviour Analysis Australia. (2018), ABAA Newsletter, Available at https://auaba.com.au/wp-content/uploads/2013/11/ABAA-Newsletter-2.1April2018.pdf

Brown, F., Michaels, C.A., Oliva, C.M. and Woolf, S.B. (2008), "Personal paradigm shifts among ABA and PBS experts". Journal of Positive Behavior Interventions, Vol. 10 No. 4, pp. 212-227.

Carr, J.E. \& Sidener, T.M. (2002), “On the relation between applied behaviour analysis and positive behavioural support", The Behavior Analyst, Vol 25 No 2, pp. 245-253.

Carr, E.G., Dunlap, G., Horner, R.H., Koegel, R.L., Turnbull, A.P., Sailor, W., Anderson, J.L., Albin, R.W., Kern Koegel, L. and Fox, L. (2002), "Positive behavior support: Evolution of an applied science”, Journal of Positive Behavior Interventions, Vol. 4 No. 1, pp. 4-16.

Chatman, S. (1978), Story and discourse: Narrative structure in fiction and film, Cornell University Press, New York. 
Coalition of Behavioral Science Organizations. (2018), Shared values and guiding principles of the Coalition of Behavioral Science Organizations, available at: https://evolutioninstitute.org/new.evolution-institute.org/wpcontent/uploads/2018/06/Coalition_Shared_Values_06-28-2018.pdf (accessed 1 July 2018).

Couper, J. (2004), "Who should pay for intensive behavioural intervention in autism? A parent's view", Journal of Paediatrics and Child Health, Vol 40 No 9-10, pp. 559-561.

Critchfield, T.S. (2015), "PBIS may not qualify as classical applied behaviour analysis. So what?", Behavior Analysis in Practice, Vol. 8 No. 1, pp. 99-100.

Critchfield, T.S. and Reed, D.D. (2017), “The fuzzy concept of applied behaviour analysis research", The Behavior Analyst, Vol. 40 No. 1, pp. 123-159.

Dearing, J.W. \& Cox, J.G. (2018), “Diffusion of innovations theory, principles, and practice", Health Affairs, Vol. 37 No. 2, pp. 183-190.

Denne, L. (2017), Positive behaviour support (PBS). Impact of the PBS Academy, available at: warwick.ac.uk/fac/soc/impact/policybriefings/pbs_academy_policy_briefing_final.pdf (accessed 15 February 2018).

Dillenburger, K., McKerr, L. \& Jordan, J. (2014), “Lost in translation: Public policies, evidence-based practice, and autism spectrum disorders", International Journal of Disability, Development and Education, Vol. 61, No. 2, pp. 134-151.

Dillenburger, K., Rottgers, H., Dounavi, K., Sparkman, C., Keenan, M., Thyer, B. \& Nikopoulos, C. (2014), “Multidisciplinary teamwork in autism: Can one size fit all?” The Australian Educational and Developmental Psychologist, Vol 31 No 2, pp. 97-112. 
Dunlap, G., Carr, E.G., Horner, R.H., Zarcone, J.R. and Schwartz, I. (2008), “Positive behaviour support and applied behaviour analysis: A familial alliance”, Behavior Modification, Vol. 32 No. 5, pp. 682-698.

Dunlap, G., Sailor, W., Horner, R.H. and Sugai, G. (2009), “Overview and history of positive behaviour support”. In Sailor, W., Dunlap, G., Sugai, G. and Horner, R. (Eds.), Handbook of positive behaviour support, Springer, New York, NY, pp. 3-16.

Filter, K.J. (2007), "Positive behaviour support: Considerations for the future of a model", The Behavior Analyst, Vol. 30 No. 1, pp. 87-89.

Fisher, W.W., Groff, R.A. \& Roane, H.S. (2011), “Applied behavior analysis. History, philosophy, principles, and basic methods". In Fisher, W.W., Piazza, C.C., \& Roane, H.S. (Eds.), Handbook of applied behavior analysis, Guildford, New York, NY, pp. 316.

Garbacz, S.A., McIntosh, K., Eagle, J.W., Dowd-Eagle, S.S., Hirano, K.A. and Ruppert, T. (2016), "Family engagement within schoolwide positive behavioral interventions and supports", Preventing School Failure, Vol. 60 No. 1, pp. 60-69.

Gore, N.J., McGill, P., Toogood, S., Allen, D. Hughes, J.C., Baker, P., Hastings, R.P., Noone, S.J. and Denne, L. (2013), “Definition and scope for positive behavioural support", International Journal of Positive Behavioural Support, Vol. 3 No. 2, pp. 14-23.

Grey, I., Lydon, H. \& Healy, O. (2016), "Positive behaviour support: What model of disability does it represent? Journal of Intellectual and Developmental Disability, Vol 41 No 3, pp. 255-266.

Guercio, J.M. and Murray, W.J. (2014), "Licensure for behaviour analysts: The path to responsible and cooperative action", Behavioral Interventions, Vol. 29 No. 3, pp. 225 240. 
Hayward, B.A., McKay-Brown, L. \& Poed, S. (in press), "Positive behaviour support in Australian disability policy, and its future with the National Disability Insurance Scheme (NDIS)", Research and Practice in Intellectual and Developmental Disabilities.

Horner, R.H. and Dunlap, G. (2012), "Future directions for TASH: Combing values and science", Research and Practice for Persons with Severe Disabilities, Vol. 37 No. 2, pp. $111-115$.

Horner, R.H. and Sugai, G. (2015), “School-wide PBIS: An example of applied behaviour analysis implemented at a scale of social importance", Behavior Analysis in Practice, Vol. 8 No. 1, pp. 80-85.

Horner, R.H. and Sugai, G. (2018), "Future directions for positive behaviour support: A commentary", Journal of Positive Behavior Interventions, Vol. 20 No. 1, pp. 19-22.

Johnson, J.M., Foxx, R.M., Jacobson, J.W., Green, G. and Mulick, J.A. (2006), “Positive behaviour support and applied behaviour analysis", The Behavior Analyst, Vol. 29 No. 1, pp. 51-74.

Jones, B.M. \& Mazzucchelli, T.G. (2018), "Remembering Jay S. Birnbrauer”, Behaviour Change, Vol 34 No 4, pp. 279-285.

Keenan, M. \& Dillenburger, K. (2011), “When all you have is a hammer...: RCTs and hegemony in science", Research in Autism Spectrum Disorders, Vol 5 No 1, pp. 1-13.

Kern, L. and Lane, K.L. (2018), “Considerations for the future of JPBI: Invited commentaries in JPBI [editorial]", Journal of Positive Behavior Interventions, Vol. 20, No. 1, p. 3.

Kincaid, D., Dunlap, G., Kern, L., Lane, K.L., Bambara, L.M., Brown, F., Fox, L. \& Knoster, T.P. (2016), "Positive behaviour support: A proposal for updating and refining the definition”, Journal of Positive Behavior Interventions, Vol 18 No 2, pp. 69-73. 
LaVigna, G.W. and Willis, T.J. (2012), “The efficacy of positive behavioural support with the most challenging behaviour: The evidence and its implications", Journal of Intellectual and Developmental Disability, Vol. 37 No. 3, pp. 185-195.

Ledford, J.R., Hall, E., Conder, E. \& Lane, J.D. (2016), "Research for young children with autism spectrum disorders: Evidence of social and ecological validity", Topics in Early Childhood Special Education, Vol 35 No 4, pp. 223-233.

Lieblich, A., Tuval-Mashiach, R. \& Zilber, T. (1998), Narrative research: Reading, analysis and interpretation, Sage, London.

Lloyd, B.P. \& Kennedy, C.H. (2014), “Assessment and treatment of challenging behaviour for individuals with intellectual disability: A research review", Journal of Applied Research in Intellectual Disabilities, Vol 27 No 3, pp. 187-199.

Moore, J. \& Cooper, J.O. (2003), “Some proposed relations among the domains of behavior analysis", The Behavior Analyst, Vol 26 No 1, pp. 69-84.

Murphy, G. (2017), “The NICE guidelines and quality standards on learning disabilities and behaviour that challenges", Tizard Learning Disability Review, Vol 22 No 2, pp. 71-81.

National Institute for Health and Care Excellence [NICE]. (2017), "Challenging behaviour and learning disabilities: Prevention and interventions for people with learning disabilities whose behaviour challenges", available at: www.nice.org.uk/guidance/ng11 (accessed 15 February 2018).

Noone, S., \& Chaplin, J. (2017), “Overcoming the reluctance to adopt the behavioural principles in positive behavior support: Defining the role for clinical psychologists", Clinical Psychology Forum, Vol 290, pp. 19-24.

Normand, M.P. \& Kohn, C.S. (2012), “Don't wag the dog: Extending the reach of applied behavior analysis", The Behavior Analyst, Vol 36 No 1, pp. 109-122. 
Prior, M., Roberts, J.M.A., Rodger, S. \& Williams, K. (2011). A review of the research to identify the most effective models of practice in early intervention for children with autism spectrum disorders. Available at https://www.dss.gov.au/sites/default/files/documents/10_2014/review_of_the_research _report_2011_0.pdf

Repp, A.C. and Singh, N.N. (1990), Perspectives on the use of nonaversive and aversive interventions for persons with developmental disabilities, Sycamore, Sycamore, IL.

Rogers, E.M. (2003). Diffusion of innovations (fifth edition), Free Press, New York, NY.

Rotholz, D.A. \& Ford, M.E. (2003), “Statewide system change in positive behaviour support”, Mental Retardation, Vol 41 No 5, pp. 354-364.

Scott, T.M. (2007), "Issues of personal dignity and social validity in schoolwide systems of positive behaviour support", Journal of Positive Behavior Interventions, Vol. 9 No. 2 , pp. 102-112.

Shook, G.L. \& Johnson, J.M. (2011), “Training and professional certification in applied behaviour analysis”. In Fisher, W.W., Piazza, C.C. \& Roane, H.S. (Eds.), Handbook of applied behavior analysis. Guildford, New York, pp. 498-510.

Smith, T. (2013), “What is evidence-based behaviour analysis?”, The Behavior Analyst, Vol 36 No 1, pp. 7-33.

Sturmey, P. (2014), “Evidence-based practice. An introduction”. In Sturmey, P. \& Didden, R. (Eds), Evidence-based practice and intellectual disabilities. Wiley Blackwell, West Sussex, pp. 3-28.

Valentine, K. (2010), “A consideration of medicalisation: Choice, engagement and other responsibilities of parents of children with autism spectrum disorder", Social Science \& Medicine, Vol 71 No 5, pp. 950-957. 
Wacker, D.P. \& Berg, W.K. (2002), "PBS as a service delivery system”, Journal of Positive Behavior Interventions, Vol 4 No 1, pp. 25-28.

Wejnert, B. (2002), “Integrating models of diffusion of innovations: A conceptual framework", Annual Review of Sociology, Vol. 28, pp. 297-326.

Table 1. Wejnert's (2002) conceptual framework for diffusion of innovations.

\begin{tabular}{|c|c|c|}
\hline Component & Variable & Definition \\
\hline \multirow[t]{2}{*}{$\begin{array}{l}\text { Characteristics of } \\
\text { the innovation }\end{array}$} & $\begin{array}{l}\text { Public versus private } \\
\text { consequences* }\end{array}$ & $\begin{array}{l}\text { The impact of adoption of the } \\
\text { innovation on an adopter or other } \\
\text { person }\end{array}$ \\
\hline & Benefit versus cost* & $\begin{array}{l}\text { Variables relate to monetary \& } \\
\text { nonmonetary, direct and indirect costs, } \\
\text { or risks associated with the adoption of } \\
\text { the innovation }\end{array}$ \\
\hline \multirow{6}{*}{$\begin{array}{l}\text { Characteristics of } \\
\text { individuals or } \\
\text { groups that affect } \\
\text { the adoption of the } \\
\text { innovation }\end{array}$} & Social entity & $\begin{array}{l}\text { The nature of adopting the innovation is } \\
\text { different for an individual person } \\
\text { compared to a group of persons }\end{array}$ \\
\hline & $\begin{array}{l}\text { Familiarity with the } \\
\text { intervention* }\end{array}$ & $\begin{array}{l}\text { The familiarity with the innovation } \\
\text { relates to how radical or novel it is }\end{array}$ \\
\hline & Status characteristics & $\begin{array}{l}\text { The prominence of a person's relative } \\
\text { position within a group }\end{array}$ \\
\hline & $\begin{array}{l}\text { Socioeconomic } \\
\text { characteristics }\end{array}$ & $\begin{array}{l}\text { The characteristics of an individual, not } \\
\text { the conditions in the environment } \\
\text { external to the individual }\end{array}$ \\
\hline & $\begin{array}{l}\text { Position in social } \\
\text { networks }\end{array}$ & $\begin{array}{l}\text { The variables that mediate the } \\
\text { transmission and absorption of } \\
\text { information about the innovation } \\
\text { between members of societal structures }\end{array}$ \\
\hline & Personal characteristics & $\begin{array}{l}\text { The 'psychological strength' of } \\
\text { individuals who adopt the innovation }\end{array}$ \\
\hline \multirow{2}{*}{$\begin{array}{l}\text { Environmental } \\
\text { contexts affecting } \\
\text { the adoption of the } \\
\text { innovation }\end{array}$} & Geographical settings* & $\begin{array}{l}\text { Geography and ecology of the adopter's } \\
\text { environment }\end{array}$ \\
\hline & Societal culture* & $\begin{array}{l}\text { The aspects of societal culture which } \\
\text { affect adopters }\end{array}$ \\
\hline
\end{tabular}




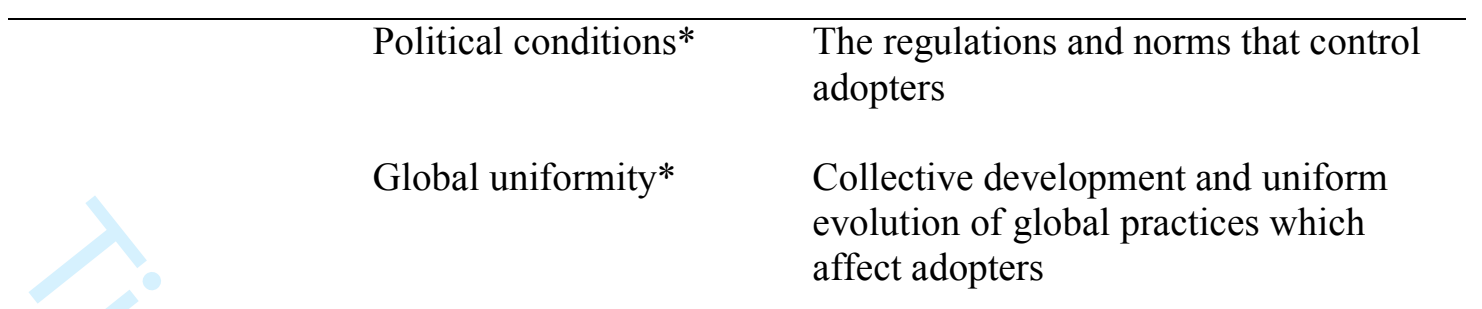

Variables marked with * are discussed in the text. 